\title{
Infrastructure Asset Management: Referees 2019
}

The following is a list of referees who have reviewed papers for Infrastructure Asset Management between 1 December 2018 and 30 November 2019. The Institution of Civil Engineers (ICE) is very grateful for their assistance.

We are continually looking for suitable reviewers for papers submitted to Infrastructure Asset Management. Papers published in the ICE journals must be submitted to at least two independent referees to judge accuracy, style, impact, importance and interest.

Mohammad Hosein Abbasi

Bryan Adey

Elshan Ahani

Saeed Alqadhi

Zaid Alyami

Sruthi Anand

Vahid Balali

Sana Balouch

David Bayliss

Basuraj Bhowmik

Frederick Bloetsche

Marcel Burkhalter
Chen-Yu Chang

Mike Dixon

Craig Ellis

Deepthi Epaarachchi

Mehran Eskandari Torbaghan

Koorosh Gharehbaghi

Urs Grunicke

Peter Hallsworth

Ciaran Hanley

Timo Hartmann

Oliver Heidrich

Peter Jay
If you are interested in reviewing articles on any topic related to infrastructure asset management, please submit your name, qualifications or CV, and areas of expertise. We are in need of individuals who will agree to review papers in a timely fashion (within 3 to 4 weeks of receipt) and provide confidential feedback to the Editorial Advisory Panel concerning the quality of the paper and any suggested revisions that would be appropriate.

If you are such a person, please contact Kirsten Buchanan (tel.: +44 (0)207 665 2204; e-mail: kirsten.buchanan@icepublishing.com) for more information on the referee process.

lan Jenkinson

Sachidanand Joshi

Maria Kakouratou

Murat Karacasu

Clemens Kielhauser

Andy Kirwan

Samuel Labi

Maria Limongelli

Mohammad Mahoud

Alireza Mohammadi

Alfredo Nunez

Emeka Osaji
Natalia Papathanasiou

Jennie Phillips

Ali Saeed

Xiomara Sanchez-Castillo

Manuel Schafer

Laura Steinberg

Trevor Taylor

Solomon Tesfamariam

Raghu Tirumala

Kieran Tully

Xian-Xun Yuan

Zhanmin Zhang 